\title{
Game-based ICT Project Formulation based on Agile Approach for Skills Development
}

\author{
Vega, L., Cancela, N., Quintero, R. and Zepeda, L. \\ Instituto Tecnológico de Culiacán
}

\begin{abstract}
The project we proposed seeks to develop in students the skills needed to manage projects that arise in different areas of ICT. In this way, the project can be used in many curriculum courses through the professor's particular adaptation. Engineering and project management subjects can be integrated.

Our project design merges Scrum method's principles, values and practices (an emerging agile method, whose skills are in high demand in ICT's labor market) and game-based learning techniques (building a LEGO city) to encourage students skills development (an educational approach that integrates different knowledge in the learning process to encourage students skills development).
\end{abstract}

Keywords: Game-based learning, agile methods, Scrum, Software Engineering, skills development.

\section{Introduction}

As a mean to facilitate meaningful learning, students are required to develop projects in a great number of the curriculum courses form the IT careers at Tecnológico de Culiacán. (Computer Systems Engineering, Information Technology and Communication or Computer Science). In most cases, this courses do not provide the framework and tools that allow students to drive their project in a systematic and professional way. Most projects are done intuitively, with what the effort made by the student is not take in to account as an educational element of his learning process.

Our project aims to be a framework to address these shortcomings by defining a systematic and well defined project management method based on the principles, practices and values of agile methods, typical of many of the IT projects which students will have to face in their future practice.

The project aims to help those teachers who require a framework for the definition of their student's projects and where they would only have to integrate their particular course content. This would offer students the basic method for their project management, which seek that the proposed project has possibility for connections with any course that is characterized as we propose.

Our project proposal is based on an agile project management method called Scrum, which is grounded on the use of game-based techniques for a better method understanding. The reason why this technique is selected is because it is intended to further the student's knowledge (know-how and know-how-to-be), and that he develops skills related to knowhow-to-transfer having the game as a mean and the project final product as an end [1]. 
The general skill that this project aims to achieve is that the student becomes able to accomplish ICT projects using the principles, practices and values recommended by Scrum agile project management method [2].

\section{Methodology}

\subsection{Background}

The framework we propose is defined based on authors experiences teaching ICTs courses such as Introduction to ICT, Web Programming, Programming and Software Engineering. We have taken these courses as practical experiences to support our proposal adaptability.

Linking this framework with other courses will be made within engineering activities established by the agile method. For project definition, a set of gaps is established to be filled upon specific activities keeping in mind final product construction chosen by the teacher. That is, the project is a framework that can be "tropicalized" for the course we want to link. Therefore, this project aims to teach how to make projects.

\subsection{Early Work}

Until now, we have successfully tested the first of three educational scenarios:

Educational Scenario 1 consists of introducing agile development principles through the construction of a city build with LEGO blocks. Specific Scrum method's techniques and tools are presented by doing the following basic activities: Definition of Scrum agile development process [2], Selection and adaptation of agile development techniques [3], Incorporation of skill-based approach [4] [5] and Incorporation of learning technique based on games (LEGO) [6].
Educational Scenario 2 assess student's knowledge and skills on agile development principles application through the design and development of a videogame by observing: Selection and adaptation of agile development techniques in the Game Design [2][7] and Incorporation of skill-based approach on Game Design [4] [5].

Educational Scenario 3 provides the student with a realistic and most likely labor market situation demanding a software development solution. Observation consists on how this is face through the design and agile development of an administrative application. Main activities are: Selection and adaptation of agile development techniques [2] and Incorporation of skill-based approach through the development of projects [7] [8].

Early observations of Educational scenario 1 are explained below.

The design begins with the definition of three major moments or course stages: Opening, Development and Closing. Specific strategies are defined for the implementation of each moment. They include a set of particular actions to integrate agile method techniques with most appropriate game rules in order to produce student's knowledge and skills as planned for the teacher at that exact stage of the course.

Below we include the main sequence used to design our pilot project:

1. Moment identification.

2. Strategies selection and definition to implement at the Moment.

3. Activities selection and description to achieve strategies.

4. Agile method techniques selection and definition to complete activities.

5. Game techniques selection and definition to achieve activities. 
6. Material selection and description for selected game techniques.

7. Knowledge description to be produce with the completion of the activities.

8. Skills description to be develop in order to achieve the knowledge.

For the Opening Moment four strategies were implemented: Team organization, Project outline Preparation, ProductBacklog construction, and Project Estimation. For Development Moment, selected strategies are repeated at least three Sprints, these were: Sprint Planning, Sprint Execution and Sprint Review. Finally, for Closing Moment, just one strategy was selected: Discussion, because it's implementation requires many activities and a significant amount of time to be completed.

During Opening Moment, strategies selected aim students to begin defining LEGO city buildings characteristics and places by drawing on a white board possible designs. For each type of building or place (house, shop, school, church, hospital, river, bridge, etc.) students create a card containing its characteristics. These cards are called User Stories. Later on, that set of User Stories will originate a Product-Backlog. To close this Moment, students, with teacher guidance, estimate and validate User Story size through any of two techniques that allow focus on value assignment: Track size (with its origins in software engineering) or Poker game (a special adapted version).

In the course of Development Moment, strategies are geared to perform a complete cycle of the project (planning, doing and reviewing a Sprint) based on what was estimated at the Opening Moment. Students move Product-Backlog's User Stories to select those that will be held in the next Sprint according to what customer assumes of higher value. Each
Sprint is consider as an iteration or project cycle.

Closing Moment allows students to show the final product to the rest of the class. The teacher conducts a comprehensive exercise for retrospective and metacognition supported on the following questions: What students observed? How they felt working with Scrum? How were short iterations? How accurate were estimations?

\section{Results}

Evidence generated as a result of the propose methodology application is considered in accordance to Cázares classification [4]. We mapped several agile methods artifacts into such evidences but also included those originated by game-based, as we explain below.

\subsection{Product Evidence}

Evidence whose purpose is to manage all knowledge: know-how, know-how-to-be, know-how-to-transfer. They are obtained from comprehensive evidence and are tangible. In our case they were: Project's final product: A LEGO city, ProductBacklog, Sprint-Backlog and Burn-down chart.

\subsection{Knowledge Evidence}

With an emphasis on knowledge, these evidences are intended to determine knowledge gained and promote different learning strategies. They consider knowledge as a mean to an end. They were: Product-Backlog, User Stories size estimation and User Stories for each Sprint.

\subsection{Performance Evidence}

They are a way to demonstrate skills acquisition by showing capability formed 
for a purpose. They work with emphasis on know-how-to-create and know-howto-transfer. Examples of this evidence were: Project's progress stages and final results presentation, Acceptance testing documents of Requirements verification based on User Stories and On-time activities achievement.

\subsection{Attitude Evidence}

Are those who work around performance values converge in the construction of skills, knowledge emphasize know-howto-be and know-how-to-create. Here they were: Poker game [3] (Delphi Technique): Listen attentively and respectfully to all team members' views, Retrospective: Rating attentive to the history of team performance at both, Sprint and entire project and, Active participation as team member.

Project's final product completion allows student to respond to metacognitive questions that arise accordingly to Scrum's method Retrospective stage. Some examples are: Is the student aware of the role played by Engineering and Project Management in his career education? Is there any student's logical and well defined forms for project construction that can be identify? Is the student aware of thinking processes involved in the realization of his projects?

\section{Conclusions and Further Work}

The proposed framework successfully integrated the principles, values and practices of Scrum method techniques in game-based learning to promote skills development as intended from the beginning. However, as the main objective of our project proposal aims to teach carryout projects in general, teacher must plan on for each course in a particular project design; taking into account the educational scenario of the group, at that time [4].
In the future, this may contribute to the idea of an "integrated project", where the design is not limited to one particular course, but as a Common Denominator of a set of subjects whose content allows for such integration. While this is not novelty in some international universities, it still is a major challenge in our public educational system. Another important task considered to be perform in the near future, is the inclusion of the Octagon assessment model [4][5], which allows a smooth transition between assessment and grading.

\section{References}

[1] E. Morin, "Seven Complex Lessons in Education for the Future (Education on the Move)", UNESCO 2001.

[2] I. Somerville, "Software Engineering", 9th Edition, Addison-Wesley 2010.

[3] J. Grenning, "Planning Poker". Delphi Technique (Popularized by Mike Cohn). Available at: http://en.wikipedia.org/wiki/Planning _poker).Visited: April 2013.

[4] L. Cázares Aponte, "Estrategias educativas para fomentar competencias: crearlas organizarlas, diseñarlas y evaluarlas (CODE)", First Edition, Trillas, Mexico, 2011.

[5] L. Cázares and F. Cuevas, "Planeación y Evaluación Basados en Competencias, fundamentos $y$ prácticas para el desarrollo de competencias, desde preescolar hasta posgrado", First Edition, Trillas, Mexico, 2007.

[6] A. Krivitsky, "A Multi-Team, FullCycle, Product-Oriented Scrum Simulation with LEGO Bricks, the Small \& Medium Business Edition". Available at: www.lego4scrum.com). Visited: April 2013. 
[7] C. Keith, “Agile Game Development with Scrum", Addison Wesley Signature. 2010.

[8] K. Claypool and M. Claypool, "Teaching Software Engineering Through Game Design". Proceedings of the Innovation and Technology in Computer Science Education (ITiCSE) Conference, Lisbon, Portugal. June 2005. 